\title{
Microscopic Findings Baseline Flag
}

National Cancer Institute

\section{Source}

National Cancer Institute. Microscopic Findings Baseline Flag. NCI Thesaurus. Code C117597.

An indication or description that microscopic findings data is a baseline value. 